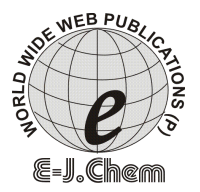

http://www.e-journals.net

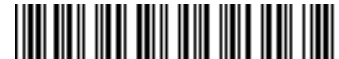

ISSN: 0973-4945; CODEN ECJHAO

E-Journal of Chemistry

Vol. 3, No.3, pp 117-121, July 2006

\title{
The Reaction of Aromatic Aldehydes and 1,3-Cyclohexanedione in Aqueous Media
}

\author{
LIU LI-BIN, JIN TONG-SHOU *, HAN LI-SHA, \\ LI MENG, QI NA, LI TONG-SHUANG \\ College of Chemistry and Environmental Science, \\ Hebei University; Hebei Province, \\ Baoding 071002, P. R. China.
}

Received 10 January 2006; Accepted 14 April 2006

\begin{abstract}
The reaction of aromatic aldehyde and 1,3-cyclohexanedione in aqueous media has been catalyzed by $p$-dodecylbenezenesulfonic acid (DBSA) or sodium dodecyl sulfate (SDS) and yields two products: 9-aryl-1, 8-dioxooctahydroxanthene derivatives and 2,2'-arylmethylene bis(3hydroxy-2-cyclohexene-1-one). This method provides several advantages such as good yield, simple work-up procedure and environment friendly.
\end{abstract}

Keywords: 9-aryl-1, 8-dioxooctahydroxanthene derivatives; p-dodecylbenezenesulfonic acid (DBSA); sodium dodecyl sulfate (SDS); synthesis

\section{Introduction}

In recent years, polyfunctionalized benzopyrans and their derivatives have attracted strong interest due to their useful biological and pharmacological properties, such as anticoagulant, spasmolytic, diuretic, antianaphylactin, anticancer. ${ }^{1}$ In addition, they also constitute a structural unit of a series of natural products ${ }^{2}$ and because of the inherent reactivity of the inbuilt pyran ring are versatile synthesis. ${ }^{3}$ Furthermore, these compounds can be employed as cosmetics, pigments ${ }^{4}$ and utilized as potential biodegradable agrochemicals. ${ }^{5}$ Thus, synthesis of the heterocyclic nucleus is of much current importance. Octahydroxanthene derivatives containing a structural unit of benzopyrans can be used as antispasm ${ }^{6}$ and fluorescent fuel ${ }^{7}$. The tetraketones and their enol forms are the precursors of synthesis of 
acridines, xanthenes and thiaxanthenes which contain structures such as dihydropyridine, pyran and thiapyran. It has been reported ${ }^{8-11}$ that the reaction of aromatic aldehyde and 1,3cyclohexanedione can yield 9-aryl-1,8-dioxo- octahydroxanthene and their derivatives and 2,2'-arylmethylene bis (3-hydroxy-2-cyclo- hexene-1-one) by many methods. However, the use of $p$-dodecylbenezenesulfonic acid (DBSA) or sodium dodecyl sulfate (SDS) as the catalyst in aqueous media for the synthesis of 9-aryl-1,8-dioxo- octahydroxanthene and their derivatives and 2,2'-arylmethylene bis(3-hydroxy-2-cyclohexene-1-one) has not been reported. Herein, we wish to synthesize 9-aryl-1,8-dioxooctahydroxanthene derivatives and 2,2'- arylmethylene bis(3-hydroxy-2-cyclohexene-1-one) using $p$-dodecyl- benezenesulfonic acid (DBSA) or sodium dodecyl sulfate (SDS) as the catalyst in aqueous media.

At the beginning of the new century, a shift in emphasis in chemistry is apparent with the desire to develop environmentally benign routes to a myriad of materials using non-toxic reagents, solvents and catalysts ${ }^{12}$ Recently "ideal synthesis" was defined as one in which the target compound is generated in one step, in quantitative yield from readily available and inexpensive starting materials in a resource-effective and environmentally acceptable process. ${ }^{13}$ Recently organic reactions in water without use of harmful organic solvents have attracted much attention, because water is a cheap, safe, and environmentally benign solvent. ${ }^{14}$ DBSA and SDS have been used in a number of organic reactions as good catalysts. In the course of our investigations to develop new synthetic methods in water using DBSA and SDS as catalysts, we examined the synthesis of 9-aryl-1,8-dioxooctahydroxanthene derivatives and 2,2'-arylmethylene bis(3-hydroxy-2- cyclohexene-1-one) in water, as a green solvent. (Scheme 1)

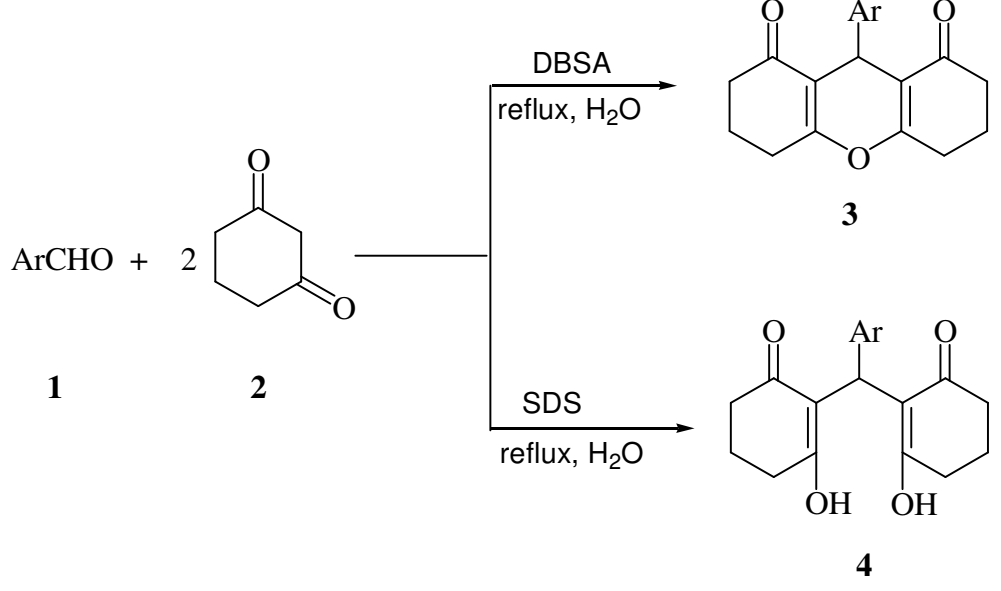

Scheme 1 Synthesis of 9-aryl-1,8-dioxooctahydroxanthene derivatives and 2,2'-arylmethylene bis(3-hydroxy-2-cyclohexene-1-one) in water

\section{Experimental}

\section{Materials and Measurements}

All liquid reagents were distilled before use. IR spectra were recorded on Bio-Rad FTS-40 spectrometer (KBr). ${ }^{1} \mathrm{H}$ NMR spectra were measured on Bruker AVANCE 400 (400 MHz) spectrometer using TMS as internal standard and DMSO as solvent. 
Procedure for the synthesis of 3 and 4 using DBSA or SDS as catalyst

A mixture of an aromatic aldehyde $(1.0 \mathrm{mmol}), 1,3$-cyclohexanedione $(2.0 \mathrm{mmol})$ and DBSA $(20 \mathrm{~mol} \%)$ or SDS $(10 \mathrm{~mol} \%)$ in water $(20 \mathrm{~mL})$ was stirred at refluxing for three hours. The progress of the reaction was monitored by thin layer chromatograph. After completion of the reactions, the mixture was cooled to room temperature and solid was filtered off and washed with $\mathrm{H}_{2} \mathrm{O}(40 \mathrm{~mL})$ and the crude products were got. The crude products 3 and 4 were purified by recrystallization by ethanol. Data of some compounds are shown below:

Compound 3c. 9-(3-Chlorophenyl)-1, 8-dioxo-octahydroxanthene:

IR (KBr): $v_{\max } 2953,2890,1672,1621,1474,1358,1201,1174,1129,847,684 \mathrm{~cm}^{-1} ;{ }^{1} \mathrm{H}$ NMR (DMSO- $\left.d_{6}\right): \delta_{\mathrm{H}} 7.13(4 \mathrm{H}, \mathrm{m}, \mathrm{ArH}), 4.56(1 \mathrm{H}, \mathrm{s}, \mathrm{CH}), 2.64\left(4 \mathrm{H}, \mathrm{m}, 2 \times \mathrm{COCH}_{2}\right), 2.29$ $\left(4 \mathrm{H}, \mathrm{m}, 2 \times \mathrm{CH}_{2}\right), 1.95\left(2 \mathrm{H}, \mathrm{m}, \mathrm{CH}_{2}\right), 1.88\left(2 \mathrm{H}, \mathrm{m}, \mathrm{CH}_{2}\right)$.

Compound 3e. 9-(2-nitrophenyl)-1, 8-dioxo-octahydroxanthene:

IR (KBr): $v_{\max } 3077,2964,2945,2896,2873,1678,1619,1520,1335,1202,1178,1130$, 823, $787 \mathrm{~cm}^{-1} ;{ }^{1} \mathrm{H}$ NMR (DMSO- $\left.d_{6}\right): \delta_{\mathrm{H}} 7.77(1 \mathrm{H}, \mathrm{d}, \mathrm{J}=6.8 \mathrm{~Hz}, \operatorname{ArH}), 7.56(1 \mathrm{H}, \mathrm{m}, \mathrm{ArH})$, $7.35(2 \mathrm{H}, \mathrm{d}, \mathrm{J}=6.8 \mathrm{~Hz}, \mathrm{ArH}), 5.40(1 \mathrm{H}, \mathrm{s}, \mathrm{CH}), 2.64\left(4 \mathrm{H}, \mathrm{m}, 2 \times \mathrm{COCH}_{2}\right), 2.27(4 \mathrm{H}, \mathrm{m}$, $\left.2 \times \mathrm{CH}_{2}\right), 1.95\left(2 \mathrm{H}, \mathrm{m}, \mathrm{CH}_{2}\right), 1.86\left(2 \mathrm{H}, \mathrm{m}, \mathrm{CH}_{2}\right)$.

Compound 3h. 9-(4-hydroxyphenyl)-1, 8-dioxo-octahydroxanthene:

IR (KBr): $v_{\max } 3379,3021,2949,2921,2892,1662,1612,1515,1361,1207,1173,1131$, 835, $762 \mathrm{~cm}^{-1} ;{ }^{1} \mathrm{H}$ NMR (DMSO- $\left.d_{6}\right): \delta_{\mathrm{H}} 9.19(1 \mathrm{H}, \mathrm{s}, \mathrm{OH}), 6.95(2 \mathrm{H}, \mathrm{d}, \mathrm{J}=8.4 \mathrm{~Hz}, \mathrm{ArH}), 6.59$ $(2 \mathrm{H}, \mathrm{d}, \mathrm{J}=8.4 \mathrm{~Hz}, \mathrm{ArH}), 4.48(1 \mathrm{H}, \mathrm{s}, \mathrm{CH}), 2.63\left(4 \mathrm{H}, \mathrm{m}, 2 \times \mathrm{COCH}_{2}\right), 2.27\left(4 \mathrm{H}, \mathrm{m}, 2 \times \mathrm{CH}_{2}\right)$, $1.94\left(2 \mathrm{H}, \mathrm{m}, \mathrm{CH}_{2}\right), 1.86\left(2 \mathrm{H}, \mathrm{m}, \mathrm{CH}_{2}\right)$.

Compound 3j. 9-(4-methylphenyl)-1, 8-dioxo-octahydroxanthene:

IR (KBr): $v_{\max } 3057,3031,2953,2892,2820,1658,1616,1510,1360,1201,1175,1126$, 819, $785 \mathrm{~cm}^{-1} ;{ }^{1} \mathrm{H}$ NMR (DMSO- $\left.d_{6}\right): \delta_{\mathrm{H}} 7.00\left(4 \mathrm{H}, \mathrm{dd}, \mathrm{J}_{1}=22 \mathrm{~Hz}, \mathrm{~J}_{2}=8 \mathrm{~Hz}, \mathrm{ArH}\right), 4.54(1 \mathrm{H}, \mathrm{s}$, $\mathrm{CH}), 2.60\left(4 \mathrm{H}, \mathrm{m}, 2 \times \mathrm{COCH}_{2}\right), 2.25\left(4 \mathrm{H}, \mathrm{m}, 2 \times \mathrm{CH}_{2}\right), 1.93\left(2 \mathrm{H}, \mathrm{m}, \mathrm{CH}_{2}\right), 1.84\left(2 \mathrm{H}, \mathrm{m}, \mathrm{CH}_{2}\right)$.

Compound 3k. 9-(3, 4-dioxymethylenephenyl)-1, 8-dioxo-octahydroxanthene:

IR (KBr): $v_{\max } 2954,2893,1658,1619,1485,1361,1201,1177,1135,853,794 \mathrm{~cm}^{-1} ;{ }^{1} \mathrm{H}$ NMR (DMSO- $\left.d_{6}\right): \delta_{\mathrm{H}} 6.64(3 \mathrm{H}, \mathrm{m}, \mathrm{ArH}), 5.94\left(2 \mathrm{H}, \mathrm{s},-\mathrm{OCH}_{2} \mathrm{O}-\right), 4.51(1 \mathrm{H}, \mathrm{s}, \mathrm{CH}), 2.61$ $\left(4 \mathrm{H}, \mathrm{m}, 2 \times \mathrm{COCH}_{2}\right), 2.29\left(4 \mathrm{H}, \mathrm{m}, 2 \times \mathrm{CH}_{2}\right), 1.95\left(2 \mathrm{H}, \mathrm{m}, \mathrm{CH}_{2}\right), 1.86\left(2 \mathrm{H}, \mathrm{m}, \mathrm{CH}_{2}\right)$.

\section{Results and Discussion}

In a typical general experimental procedure, a solution of an aromatic aldehyde and 1, 3cyclohexanedione in water was heated under reflux water in the presence of a catalytic amount of DBSA $(20 \mathrm{~mol} \%)$ or SDS $(10 \mathrm{~mol} \%)$ for a certain period of time required to complete the reaction, the corresponding 9-aryl-1,8-dioxooctahydroxanthene derivatives and 2,2'-arylmethylene bis(3- hydroxy-2-cyclohexene-1-one) were obtained in good yields. The results are summarized in Table 1.

As shown in Scheme 1, the different products were obtained using different catalyst in this reaction. In a typical general experimental procedure, aromatic aldehyde and 1,3cyclohexanedione reacted in the presence of a catalytic amount of DBSA or SDS, the corresponding products $\mathbf{3}$ and $\mathbf{4}$ were obtained in good to excellent yields. The catalyst effect shows that acid is needed during the cyclization. 
To study the generality of this process, several examples illustrating this method for the synthesis $\mathbf{3}$ and $\mathbf{4}$ were studied. As shown in Table 1. The effect of electron and the nature of substituents on the aromatic ring did not show strongly obvious effects in terms of yields under this reaction conditions. The reaction proceeded smoothly under refluxing water to give the corresponding products $\mathbf{3}$ and $\mathbf{4}$ in good yields. Benzaldehyde and other aromatic aldehydes containing electron-withdrawing groups (such as nitro group, halide) or electrondonating groups (such as hydroxy group, alkoxyl group) were employed and reacted well to give the corresponding $\mathbf{3}$ and $\mathbf{4}$ in good to excellent yields.

Table 1 Synthesis of 9-aryl-1,8-dioxooctahydroxanthene derivatives and 2,2'-arylmethylene bis(3-hydroxy-2-cyclohexene-1-one) in aqueous media

\begin{tabular}{|c|c|c|c|c|}
\hline \multirow[b]{2}{*}{$\mathrm{Ar}$} & \multirow[b]{2}{*}{ Product } & \multirow[b]{2}{*}{ Yield $^{\mathrm{a}}(\%)$} & \multicolumn{2}{|c|}{ M. P. $/{ }^{0} \mathrm{C}$} \\
\hline & & & Found & Reported \\
\hline \multirow[t]{2}{*}{$\mathrm{C}_{6} \mathrm{H}_{5} \mathbf{1 a}$} & $\mathbf{3 a}$ & 91 & $272-273$ & $270-271^{8}$ \\
\hline & $4 \mathbf{a}$ & 64 & $210-211$ & $205-207^{10}$ \\
\hline 4- $\mathrm{ClC}_{6} \mathrm{H}_{4} \mathbf{1 b}$ & $\mathbf{3 b}$ & 84 & $288-290$ & $289-291^{8}$ \\
\hline $3-\mathrm{ClC}_{6} \mathrm{H}_{4} \mathbf{1 c}$ & $3 c$ & 80 & $276-277$ & \\
\hline \multirow[t]{2}{*}{$2-\mathrm{ClC}_{6} \mathrm{H}_{4} \mathbf{1 d}$} & 3d & 78 & $254-255$ & $250-251^{8}$ \\
\hline & $4 d$ & 67 & $235-237$ & $238-240^{10}$ \\
\hline $2-\mathrm{NO}_{2} \mathrm{C}_{6} \mathrm{H}_{4} \mathbf{1 e}$ & $3 \mathbf{e}$ & 90 & $245-246$ & \\
\hline $3-\mathrm{NO}_{2} \mathrm{C}_{6} \mathrm{H}_{4} \mathbf{1 f}$ & 3f & 94 & $286-288$ & $286-288^{8}$ \\
\hline \multirow[t]{2}{*}{$4-\mathrm{NO}_{2} \mathrm{C}_{6} \mathrm{H}_{4} \mathbf{1 g}$} & $3 g$ & 86 & $263-265$ & $263^{12}$ \\
\hline & $4 g$ & 92 & $195-196$ & $191-192^{11}$ \\
\hline 4- $\mathrm{HOC}_{6} \mathrm{H}_{4} \mathbf{1 h}$ & $3 \mathbf{h}$ & 84 & $279-281$ & \\
\hline \multirow[t]{2}{*}{$4-\mathrm{CH}_{3} \mathrm{OC}_{6} \mathrm{H}_{4} \mathbf{1 i}$} & $3 \mathbf{i}$ & 88 & $196-197$ & $201-202^{8}$ \\
\hline & $4 i$ & 73 & $183-185$ & $178-180^{11}$ \\
\hline $4-\mathrm{CH}_{3} \mathrm{C}_{6} \mathrm{H}_{4} \mathbf{1} \mathbf{j}$ & $\mathbf{3 j}$ & 67 & $262-263$ & \\
\hline $3,4-\mathrm{OCH}_{2} \mathrm{OC}_{6} \mathrm{H}_{3} \mathbf{1 k}$ & $3 \mathbf{k}$ & 84 & $248-249$ & \\
\hline
\end{tabular}

${ }^{\mathrm{a}}$ Isolated yield

The catalyst plays a crucial role in the success of the reaction in terms of the rate and the yields. For example, 4-chlorobenzoaldehyde reacted with 1, 3-cyclohexanedione in the presence of $10 \mathrm{~mol} \%$ DBSA to give the product $3 \mathrm{~b}$ in modest yield $(76.6 \%)$ at refluxing water after three hours of reaction time. Increasing of the catalyst to 20 and $30 \mathrm{~mol} \%$ results in accelerating the reaction yields to $83.7 \%$ and $80.3 \%$ respectively. Use of just $20 \mathrm{~mol} \%$ DBSA in refluxing water is sufficient to push the reaction forward. Higher amounts of the catalyst did not improve the results to a greater extent. Thus, $20 \mathrm{~mol} \%$ DBSA was chosen as a quantitative catalyst for these reactions. In addition, it must be pointed out that all of these reactions were carried out in water and those products were characterized by melting point, IR and ${ }^{1} \mathrm{H}$ NMR. 


\section{Conclusions}

We have described a practical and efficient procedure for the preparation of 9-aryl-1, 8dioxooctahydroxanthene derivatives and 2,2'- arylmethylene bis(3-hydroxy-2-cyclohexene1-one). In addition, these reactions, which proceed sluggishly in organic solvents, attest to the unique property of water as a reaction medium. This procedure offers several advantages including mild reaction conditions, cleaner reaction, high yields of products as well as a simple experimental and isolated procedure which makes it a useful and attractive process for the synthesis of these compounds. Mostly important, water has been chosen as a green solvent for these reactions.

\section{References}

1 (a) Foye W O Prinicipi di Chimica Farmaceutica Piccin, Padova, Italy, 1991, 416.

(b) Andreani L L, Lapi E Boll. Chim. Farm. 1960, 99, 583. (c) Chem. Abstr., 1982, 96, 135383e. (d) Bonsignore L, Loy G, Secci D and Calignano A, Eur. J. Med. Chem. 1993, 28, 517. (e) Chem. Abstr., 1986, 104, 224915 f.

2 (a) Hatakeyama S, Ochi N, Numata H and Takano S, J. Chem. Soc. Chem. Commun. 1988, 1202. (b) Cingolant G M and Pigini M, J. Med. Chem. 1969, 12, 531.

3 O'Callaghan C N and Mc Murry T B H, J. Chem. Res. (S) 1995, 214.

4 Ellis G P The chemistry of Heterocyclic compounds. In chromenes, chromanes and Chromeones, Weissberger A and Taylor E C, New York, 1977, p 13.

5 (a) Hafez E A, Elnagdi M H, Elagamey A A and El-Taweel F A M, Heterocycles 1987, 26, 903. (b) Abdel Galil F M, Riad B Y, Sherif S M and Elnagdi M H, Chem. Lett. 1982, 1123.

6 Ji X S, Liu Y, Miao Y and Jin T, Chin. J. Pharm. Sci., 1998, 7(4), 221.

7 Zhao T F, Zhao D F, Sun X S and Cheng L B, Chem. Ind. Eng., 1998, 49(4), 515.

8 Hua G P, Li T J, Zhu S L and Zhang X J, Chin. J. Org. Chem., 2005, 25(6), 716.

9 Jonathan R D, Srinivas K R and Glen E B, Eur. J. Med. Chem., 1988, 23, 111.

10 Shanmugasundaram P, Prabahar K J and Ramakrishnan V T, J. Heterocyclic. Chem., 1993, 30, 1003.

11 Chen X D and Xu F P,Journal of Shang Hai University (natural science), 2000, 6, 375.

12 Anastas P and Williamson T, Green Chemistry, Frontiers in Benign Chemical Synthesis and Procedures, Oxford Science Publications, 1998.

13 Wender P A, Handy S L and Wright D L, Chem. Ind. (London) 1997, 765.

14 (a) Grieco P A, Organic synthesis in water, Blackie, London, 1998. (b) Li C J and Chan T H, Organic reactions in aqueous media, Wiley, New York, 1997. (c) Cornils B and Herrmann W A, Aqueous-phase Organometallic Chemistry-Concepts and Applications, Wiley-VCH, Weinheim, 1998. 


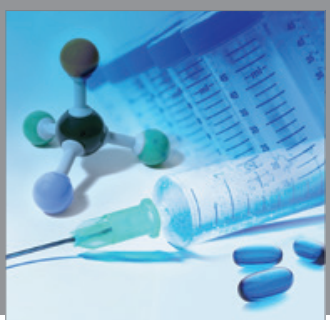

International Journal of

Medicinal Chemistry

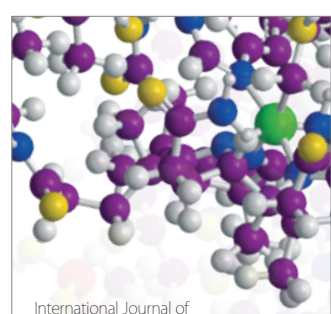

Carbohydrate Chemistry

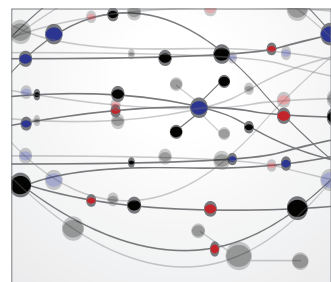

The Scientific World Journal
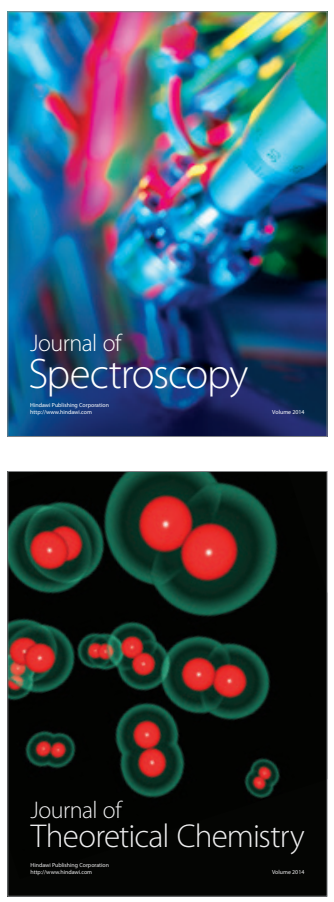
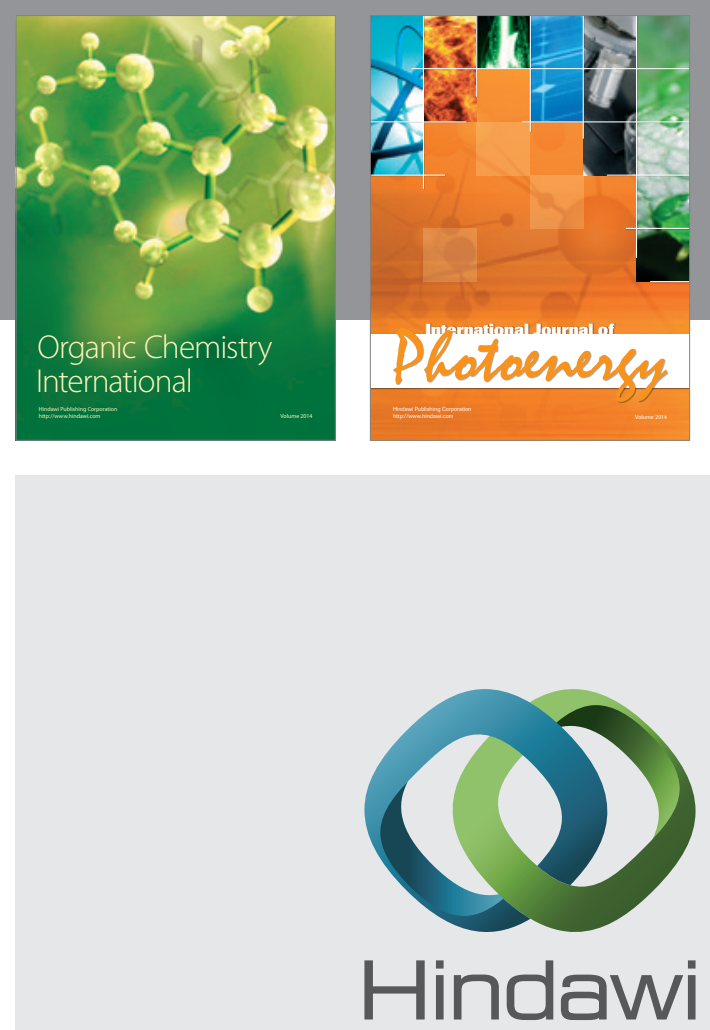

Submit your manuscripts at

http://www.hindawi.com
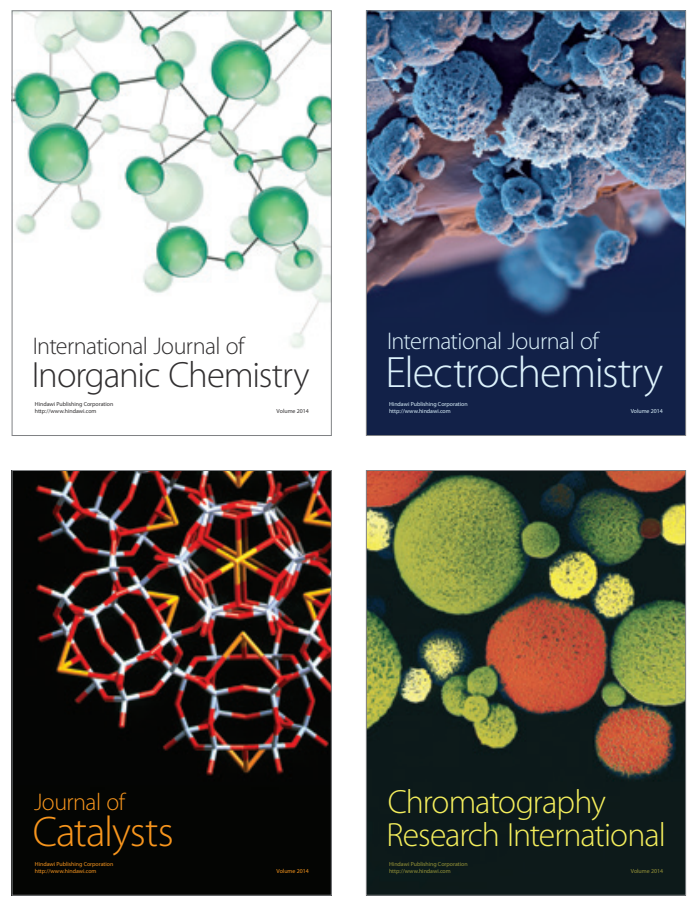
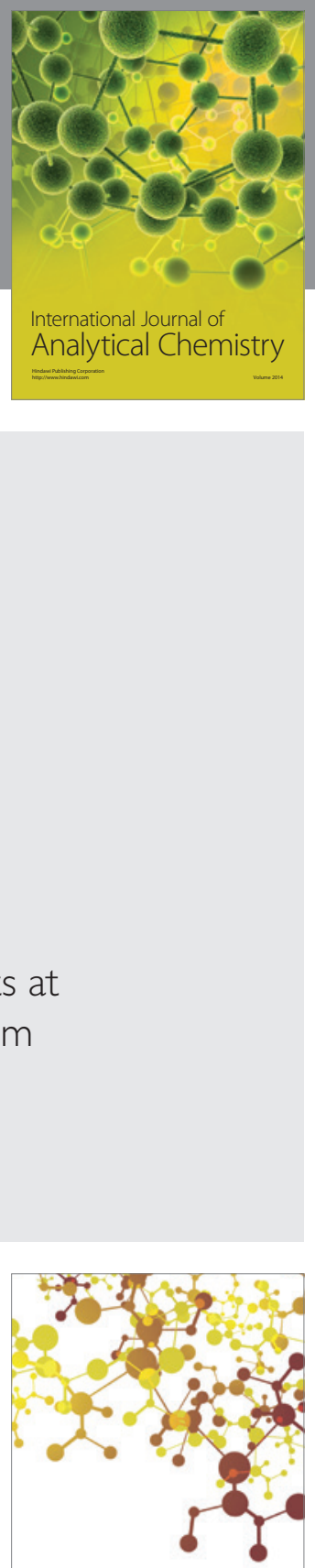

Journal of

Applied Chemistry
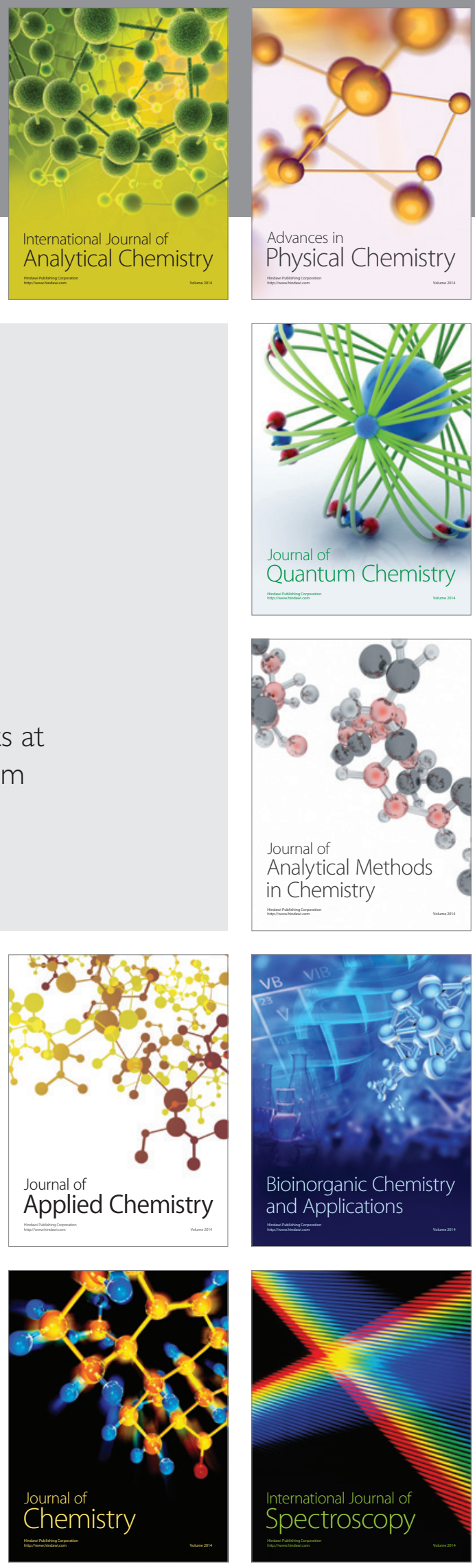